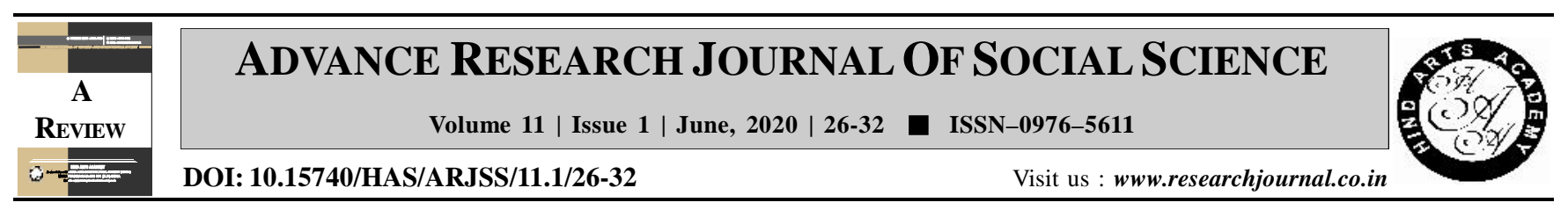

\title{
Customary practices - A great challenge to the maternal and child health
}

Suryamani Patro

P.G. Department of Home Science, SBRG Women's College, Berhampur (Odisha) India (Email : smpatro2007@ rediffmail.com)

\section{ARTICLE INFO :}

Received : 14.02 .2020

Accepted : 25.05 .2020
KEY WORDS :

\section{KEY WORDS :}

Customary practices, Maternal, Child health

HOW TO CITE THIS ARTICLE :

Patro, Suryamani (2020). Customary practices - A great challenge to the maternal and child health. Adv. Res. J. Soc. Sci., 11 (1): 26-32, DOI: 10.15740/HAS/ARJSS/11.1/26-32.Copyright@ 2020:Hind Agri- Horticultural Society 